\title{
Quem liberta quem? Percepções de libertadores de escravos no Brasil contemporâneo
}

\author{
Who frees who? Perceptions of liberators of slaves in contemporary Brazil
}

Jaqueline Gomes de Jesus ${ }^{[a]}$

\footnotetext{
[a] Doutora em Psicologia Social, do Trabalho e das Organizações pelo Instituto de Psicologia da Universidade de Brasília (UnB), Brasília, DF - Brasil, e-mail: jaquelinejesus@unb.br
}

Recebido: $24 / 04 / 2011$ Received: 04/24/2011

Aprovado: 04/11/2011 Approved: 11/04/2011

\section{Resumo}

A escravidão é um tipo de exploração da mão de obra que faz parte do mundo do trabalho desde a Antiguidade. Nos tempos atuais, diferentes organizações têm identificado e combatido a existência de trabalho escravo no Brasil, em especial em zonas rurais isoladas das Regiões Norte e Nordeste do país. A presente pesquisa investigou o campo representacional, as percepções sobre a organização do trabalho e as vivências de prazer e de sofrimento, sob o prisma da Psicodinâmica do Trabalho, de pessoas que, em diversas frentes, trabalham para a libertação de escravos no Brasil contemporâneo. A metodologia utilizada abrangeu entrevistas semiestruturadas aplicadas a dez respondentes e submetidas à análise de conteúdo temático. Os resultados indicam que as vivências de sofrimento prevaleceram. A expectativa de libertação do outro é importante para o trabalho do libertador, e a manutenção da saúde psíquica do libertador é influenciada pela percepção de uma sociedade que liberta pessoas, de modo que ocorre uma libertação do libertador quando este percebe a liberdade de outros.

Palavras-chave: Escravidão. Psicodinâmica do trabalho. Organização do trabalho. Prazer. Sofrimento.

\begin{abstract}
Slavery is a kind of exploitation of manpower that is part of the world of work since Antiquity. Nowadays, different organizations have identified and fought the existence of slave labor in Brazil, especially in isolated rural areas of the Northern and Northeastern Regions of this country. The present research investigated the representational field, the perceptions about the organization of work and the experiences of pleasure and of suffering, from the perspective of the Psychodynamics of Work, of people who, in several fronts, work for the liberation of slaves in contemporary Brazil. The used methodology included semi-structured interviews applied to ten respondents and subjected to thematic content analysis. The results indicate that the experiences of suffering prevailed. The expectation of release of the other is important for the work of the liberator, and the maintenance of the psychical health of the liberator is influenced by the perception of a society that frees people, so that a release of the liberator occurs when it perceives the freedom of others.
\end{abstract}

Keywords: Slavery. Psychodynamics of work. Organization of work. Pleasure. Suffering. 


\section{Introdução}

Este artigo resulta da dissertação de mestrado Trabalho Escravo no Brasil Contemporâneo: Representações Sociais dos Libertadores ${ }^{1}$.

0 trabalho adquire suma importância na vida dos indivíduos em função dos confrontos entre a subjetividade do trabalhador e as objetivas condições impostas pelo ambiente de trabalho (Mendes \& Morrone, 2002), resultantes das condições socioeconômicas e culturais. A Psicodinâmica do Trabalho desenvolvida por Dejours (1988) citado por Pereira (2003) considera que o conteúdo das tarefas e as relações socioprofissionais são fatores determinantes para a organização do trabalho.

0 trabalho escravo é uma instituição comum desde a Pré-História, radicalmente estruturada na História e na economia das sociedades humanas (Meltzer, 2003), e que subsistiu durante toda a Antiguidade, na Idade Média (Davis, 2001) e, depois, foi amplamente utilizada pelas economias nacionais durante o período Moderno, por meio da exploração transatlântica da mão de obra de africanos.

O termo "escravo" advém do nome "eslavo", que remonta à "época em que os germanos supriam os mercados da Europa com prisioneiros eslavos" (Meltzer, 2003, p. 16). Nessa condição, o ser humano é colocado como passivo/objeto.

O significante "escravo" resulta de um conjunto de significados preconceituosos reunidos ao longo da História da Humanidade, que cabem nas acepções de preconceito como generalização falsa com relação à caracterização de um grupo, que é feita a um membro desse grupo (Jones, 1997), e do preconceito como presunção, acerca do sujeito, de qualidades objetais atribuídas ao grupo (Allport, 1954).

\section{Trabalho escravo contemporâneo}

O trabalho escravo é, ainda hoje, uma realidade global, que se relaciona a fluxos migratórios, ao tráfico de seres humanos, e se estrutura em torno de organizações isoladas do Estado: fazendas em regiões muito afastadas dos núcleos urbanos ou, nas cidades, em casas de prostituição e no trabalho doméstico abusivo (Paiva, 2003).

Como aponta Dupas (1998, p. 107), a questão do emprego é uma questão de direitos humanos, visto que "a renda obtida do trabalho é o instrumento pelo qual o homem tem acesso aos bens e serviços essenciais a uma sobrevivência digna". Entretanto, a lógica da economia mundial tem, de tal modo, flexibilizado o emprego formal e alterado o nível e a estabilidade da renda, o que produz uma piora generalizada no quadro do desemprego em todo o globo.

Véras (2002) observa que a exclusão social integrada à cultura nacional se pauta pela concepção de tipos diferentes de pessoas:

além da humanidade formada de integrados (ricos e pobres), inseridos de algum modo no circuito das atividades econômicas e com direitos reconhecidos, há uma outra humanidade no Brasil, crescendo rápida e tristemente através do trabalho precário, no pequeno comércio, no setor de serviços mal pagos, tratados como cidadãos de segunda classe (Véras, 2002, p. 40).

Acrescente-se às palavras de Véras (2002): aqueles que são escravizados.

Segundo a Comissão Pastoral da Terra (2003), em 1984 foi confirmada a primeira grande denúncia de trabalho escravo no sul do Pará. No território brasileiro, as migrações que fornecem recursos humanos às organizações escravocratas são internas, restritas ao território nacional, englobando, principalmente, estados das regiões Nordeste e Norte (Figueira, 2001).

Dados da Procuradoria Federal dos Direitos do Cidadão, (PFDC), (2003) alertam, por exemplo, que já foi identificada escravidão na pecuária do Distrito Federal; e que $34,90 \%$ dos casos de escravidão brasileira contemporânea ocorrem no estado do Pará, principalmente nas áreas de desmatamento, pecuária e produção de carvão vegetal, que costumam empregar famílias inteiras, incluindo crianças.

Associando-se esse fato ao que Mir (2004, p. 135) pontua como "tratamento odioso frequentemente oferecido aos migrantes internos" e "efetivação de uma hierarquia social baseada num Estado

\footnotetext{
${ }^{1}$ Defendida no Instituto de Psicologia da UnB, sob orientação da Professora Maria das Graças Torres da Paz e coorientação da Professora Ângela Maria de Oliveira Almeida.
} 
que exercitaria a segregação subterrânea entre grupos étnicos e sociais" (Mir, 2004, p. 44), característicos da história e da formação cultural brasileira, aumenta-se a plausibilidade da hipótese de correlação positiva entre tráfico de seres humanos e trabalho escravo: sendo "mercadorias" ilegais, o aliciamento é a única forma de alocar os escravos de sua origem para o mercado consumidor.

\section{Escravidão no meio rural}

Dadas as particularidades socioeconômicas e educacionais do país, o agronegócio é de suma importância para o superavit da balança comercial brasileira (exportações menos importações), apesar das regulares instabilidades nesse mercado decorrentes da volatilidade nos preços internacionais das commoditties (insumos agrícolas), tais como a soja (Agrolink, 2011), com tendência de recuo e retorno aos seus valores históricos (Vidor, 2005).

0 setor agrícola brasileiro, como setor tradicional da economia, sempre esteve "articulado ao setor moderno [urbano-industrial], servindo ao processo de acumulação de capital, especialmente através de mecanismo de oferta de alimentos a preços baixos, além de ser uma fonte geradora de força de trabalho" (Sorj, Pompermayer \& Coardini, 1982, p. 10).

Os escravocratas identificados pelo governo e organismos internacionais são latifundiários que empregam intermediários, denominados "gatos", para aliciar trabalhadores pouco ou nada instruídos e sem proteção de qualquer rede social, a fim de maximizar os lucros com a exploração da mão de obra (Figueira, 2004). Além da coerção, uma das maneiras encontradas para aprisionar os trabalhadores é alegar dívidas inexistentes para com o empregador, no âmbito do transporte ou da alimentação.

A predominância da escravidão contemporânea em fazendas é um dos sintomas dos graves problemas sociais do meio rural brasileiro. A experiência do subsídio não uniforme do capitalismo agrário para o capitalismo urbano-industrial foi vivenciada no Brasil, na expressão de Florestan Fernandes (1979, p. 105), concomitantemente à "resistência sociopática à mudança social", caracterizada por "comportamentos econômicos autodefensivos e autocompensadores" (1979, p. 109) subcapitalistas.

O subcapitalismo é compreendido como um fenômeno regionalizado do capitalismo, particular- mente brasileiro, no qual as práticas capitalistas remontam, ao menos indiretamente, ao capitalismo mercantil, podendo se caracterizar, dentre outros fatores, pelo uso de mão de obra não capacitada.

O comportamento da economia agrária relatado por Fernandes (1979) e sua relação com a economia urbana é tão direta que "para que o capital possa reproduzir na economia urbana o trabalhador assalariado, é necessário que exista na economia agrária o capital que reproduz o trabalhador semilivre" (Fernandes, 1979, p. 114).

Seguindo essa lógica, a existência do trabalhador escravo em setores do campo é um dos reflexos da desproletarização da economia agrária brasileira, apontando para mazelas nas atuais condições do trabalho assalariado também no meio urbano.

\section{0 trabalho de libertar}

Apesar da opressão e dos mecanismos para contenção dos oprimidos, a exemplo do silenciamento quanto à resistência indígena, negra e popular nas Américas, em razão do potencial político-cultural de alternativa e de ruptura ao modelo instituído pelas elites (Girardi, 1996), a revolta dos escravos ao longo da História da Humanidade foi incessante.

A insurreição da colônia francesa de São Domingos, atual República do Haiti, fortalecida nos ideais da Revolução Francesa (James, 2000), é exemplo emblemático do poder das minorias ativas (Moscovici, 1981) em contestar as concepções hegemonicamente estabelecidas.

O Brasil está repleto de estórias de resistência ao regime escravocrata que não se restringem aos quilombos, espaços econômicos alternativos (Fiabani, 2005) conquistados pela resistência estratégica dos negros para elaborar táticas de combate (Moura, 1959), às revoltas urbanas, ao movimento abolicionista ou à Abolição da Escravatura no ano de 1888. A maioria dos negros já era livre, por causa de pagamentos pessoais e grupais de alforrias, além de fugas em massa que constituem, até hoje, a maior ação de desobediência civil da história do país (Conrad, 1975).

Hoje, organismos nacionais e internacionais se articulam, em um contexto de politização do social com vistas ao interesse da coletividade (Schiochet, 1999), para combater a exploração 
do trabalho escravo. O Ministério do Trabalho e Emprego (MTE), em conjunto com a Polícia Federal (PF) e o Ministério Público do Trabalho (MPT), fiscaliza, combate o trabalho escravo e coleta depoimentos dos libertos.

Entretanto, porque o pessoal capacitado nos postos de fiscalização espalhados no continental território brasileiro é insuficiente, a principal maneira de o Estado tomar conhecimento de exploração escrava é por meio de denúncias. Os denunciantes são geralmente trabalhadores que conseguem fugir ou cidadãos próximos às fazendas escravocratas ou à sociedade civil organizada, caracterizada por grupos comunitários, organizações não governamentais [ONGs], especialmente as de cunho religioso, a exemplo da Comissão Pastoral da Terra, dada sua forte presença em lugares não atendidos pelo Estado (Alves, 2004).

A estrutura organizacional brasileira de libertação dos escravizados é recente, começando o registro de operações de fiscalização do MTE em 1995. Dados do Ministério apontam que, de 1995 a 2010, foram libertados 37.870 trabalhadores escravizados em fazendas, em 2010 foram resgatados 1.318 (Ministério do Trabalho e Emprego, [MTE], 2011).

\section{Objetivo do estudo}

O fenômeno socioeconômico da escravidão contemporânea é constituído por elementos afetivos, mentais e sociais particulares, sendo esse fenômeno um determinante forte da realidade material, cognitiva e social dos atores envolvidos. Ao nível fenomenológico, as relações entre escravocratas/ opressores, escravos/oprimidos e libertadores são "elementos da realidade social" (Oliveira \& Werba, 2002, p. 105), caracterizados por "modos de conhecimento, saberes do senso comum que surgem e se legitimam na conversação interpessoal cotidiana e têm como objetivo compreender e controlar a realidade social".

A presente pesquisa objetivou investigar as percepções dos libertadores de pessoas submetidas à escravidão contemporânea quanto ao seu trabalho, orientando-se por conceitos-chave da Psicodinâmica do Trabalho, como organização e condições de trabalho, vivências de prazer e de sofrimento (Karam, 2010; Mendes \& Morrone, 2010).

\section{Métodos}

Sujeitos

Participaram da pesquisa dez $(\mathrm{n}=10)$ libertadores de escravos. Seis sujeitos representando o governo brasileiro, três sujeitos representando um organismo internacional e um sujeito representando uma organização não governamental $(\mathrm{ONG})$, sete $(\mathrm{n}=7)$ do sexo masculino e três $(n=3)$ do sexo feminino; quanto ao grau de escolaridade, nove $(n=9)$ completaram o ensino superior, e um $(\mathrm{n}=1)$ o ensino médio. Os sujeitos são identificados, conforme segue:

- Sujeito A - homem, com Ensino Superior, do governo brasileiro;

- Sujeito B - homem, com Ensino Médio, do governo brasileiro;

- Sujeito C - mulher, com Ensino Superior, do governo brasileiro;

- Sujeito D - mulher, com Ensino Superior, de organização não governamental;

- Sujeito E - homem, com Ensino Superior, de organismo internacional;

- Sujeito F - homem, com Ensino Superior, de organismo internacional;

- Sujeito G - homem, com Ensino Superior, de organismo internacional;

- Sujeito H - mulher, com Ensino Superior, do governo brasileiro;

- Sujeito I - homem, com Ensino Superior, do governo brasileiro;

- Sujeito J - homem, com Ensino Superior, do governo brasileiro.

Instrumentos

Foram aplicadas entrevistas individuais semiestruturadas, baseadas em um roteiro amplo, formadas por questões abertas relacionadas à descrição do trabalho, sentimentos em relação ao trabalho, dificuldades encontradas, concepções e sentimentos relacionados à dinâmica profissional.

\section{Procedimento}

As entrevistas foram flexibilizadas de modo a centrar-se empaticamente na pessoa do entrevistado, 
procurando reformular as questões de acordo com o desenvolvimento da conversação e estimulando o entrevistado com relação aos temas discutidos. Foram gravadas, resultando a degravação de um total de 4 horas e 30 minutos de falas, e seus dados perscrutados de acordo com a análise de conteúdo (Bardin, 1995), baseada em análise categorial temática, dividida em duas etapas.

Na primeira etapa, cada uma das dez entrevistas foi analisada por dois juízes, compondo um total de vinte $(n=20)$ juízes, entre profissionais de nível superior, graduados, pós-graduandos, mestres e doutores devidamente instruídos por orientação oral e leitura de textos instrucionais quanto às especificidades da técnica de análise categorial de conteúdo.

Os juízes, após leitura aprofundada dos vários depoimentos, investigaram os temas imbricados nas verbalizações e os classificaram em unidades semânticas denominadas "categorias", de significações manifestas e simples, com o auxílio de uma planilha para marcação de tais dados. As frequências das categorias foram registradas.

Na segunda etapa, as categorias de todas as entrevistas foram agrupadas em categorias-síntese, segundo um critério de semelhança semântica e lógica, por meio de associação de ideias.

\section{Resultados}

Foram identificados 111 temas, os quais foram organizados em nove categorias. A análise temática categorial das entrevistas indicou uma categoria-síntese para cada conjunto de três categorias: (1) organização do trabalho, (2) vivências de prazer e (3) vivências de sofrimento.

A categoria-síntese organização do trabalho foi estruturada em torno das categorias (a) dinâmica do trabalho, (b) impotência e (c) sucesso.

Dinâmica do trabalho engloba temas emotivamente neutros, essencialmente descritivos da rotina de trabalho do libertador, tais como a distribuição das tarefas, regras e normas e estrutura de subordinação. Foi indicada por verbalizações como: "Desde noventa e sete, eu venho trabalhando, bastante ativamente, na implementação final dos projetos, tanto na área tecnológica quanto social" (Sujeito F); "A gente se encontrava semanalmente, e aí, surgiram os trabalhos que são realmente, daí para frente, todos em grupo. Todo mundo decide quase tudo" (Sujeito D);
"Nós temos sete coordenações, tá? São esses coordenadores, coordenador. Como é que funciona? Nós recebemos denúncias" (Sujeito C).

Impotência engloba temas de vivência de sofrimento diretamente relacionados à rotina de trabalho do libertador, voltadas para as próprias tarefas, o modo como são executadas e suas consequências, envolvendo reforços negativos aos seus trabalhos, e foi indicada por verbalizações como: "É... com uma sensação muito... muitas vezes, de impotência, né?" (Sujeito H); "Então, está tudo mais ou menos aí, direitinho. Para sair isso daí, nossa! Teve trocentas mil reuniões, né?" (Sujeito $\mathrm{C}$ ); "A impotência e a frustração, que eu falei no início, que... é normal, é até bom que a gente se... tenha essa capacidade ter esses sentimentos..." (Sujeito $\mathrm{H}$ ).

Sucesso envolve temas de vivência de prazer diretamente relacionados à realização efetiva da tarefa ou à valorização da formação profissional do libertador. Foi indicada por verbalizações como: "Acabei caindo aqui, meio que de paraquedas, mandei currículo e me chamaram. E para minha sorte" (Sujeito E); "Trabalhando em um ambiente agradável... é bem satisfatório... é, ainda tem a parte, digamos assim, compensatória, né? O salário..." (Sujeito E); "É uma organização que... realmente... aonde você tem prazer de trabalhar pelo... pelo ambiente, pelo caráter e formação técnica das pessoas" (Sujeito F).

A Tabela 1 aponta as categorias presentes em cada entrevista, no referente à organização do trabalho, com a distribuição das frequências brutas de verbalizações de cada categoria.

A categoria dinâmica do trabalho ocupou 41\% dos conteúdos verbalizados sobre a organização do trabalho, a categoria impotência contabilizou $27 \%$ e a categoria sucesso correspondeu a $32 \%$.

A categoria-síntese vivência de sofrimento foi composta pelas categorias relativas à (a) pessoa escravizada, (b) pessoa que escraviza e (c) sociedade em que se escraviza.

A vivência de sofrimento relativa à pessoa escravizada engloba temas em que o libertador demonstrou insatisfação com a precariedade e a condição subumana da pessoa submetida ao trabalho escravo, objeto de combate de seu próprio trabalho, ou atribuiu características negativas ao escravo. Foi indicada por verbalizações como: "A gente via fotos de pessoas que tinham falecido, de pessoas que estavam machucadas, que não tinham auxílio nenhum, então, 
Tabela 1 - Quadro-resumo das categorias por entrevista - organizacão do trabalho

\begin{tabular}{cccc}
\hline Entrevistas & $\begin{array}{c}\text { Dinâmica do } \\
\text { trabalho }\end{array}$ & Impotência & Sucesso \\
\hline A & 16 & 3 & 8 \\
B & 12 & 19 & 14 \\
\hline C & 17 & 12 & 22 \\
\hline D & 27 & 7 & 13 \\
\hline E & 22 & 7 & 8 \\
\hline F & 25 & 17 & 13 \\
\hline G & 13 & 2 & 8 \\
\hline H & 21 & 28 & 27 \\
\hline I & 10 & 13 & 15 \\
\hline J & 16 & 8 & 10 \\
\hline Total & $\mathbf{1 7 9}$ & $\mathbf{1 1 6}$ & $\mathbf{1 3 8}$ \\
\hline
\end{tabular}

Fonte: Dados da pesquisa.

assim, isso tudo é muito degradante, assim, para o homem" (Sujeito D);

Quando tu vê uma menina dizer... ela está presa numa agência, onde ela tem regras e normas, onde ela precisa... ela é ameaçada de morte, ela fica presa em cativeiro, tu vê a dor, tu vê a angústia, tu vê a lesa que isso leva para a vida dessa adolescente (Sujeito $\mathrm{H}$ );

Essa mágoa, esse ressentimento, essa vontade de sair dessa situação... mas, muitas vezes, impedida, justamente, por falta de uma retaguarda, seja de políticas públicas, né? Ou de... de uma mão, um colo mesmo, de quem está do lado e que possa estar ajudando a resolver esse problema (Sujeito $\mathrm{H}$ ).

A vivência de sofrimento relativa à pessoa que escraviza engloba temas diretamente relacionados à prática escravocrata, seja praticada pelo gerenciador e guarda dos escravos, denominado "gato", ou pelo proprietário das terras, que explora mão de obra escrava pelo intermédio do gato. Foi indicada por verbalizações como: "Olha, é uma escória humana, não é? Que só pensa no lucro, pelo lucro, não importa os meios para atingir esse lucro, para competir... eu diria... que é até uma deformação de caráter" (Sujeito J); "Tem uma defecção muito grande, que ele acha que está fazendo muito por aquele indivíduo, ele diz 'Olha, se eu não colocar ele aqui, ele morre de fome. Morre de fome aí na cidade', então, ele acha que aquilo, ele já está fazendo demais" (Sujeito J); "Então, é um pessoal de muita truculência, muito articulados. Sabem se expressar muito bem, sabem manejar recursos sofisticados, de mídia, inclusive, de assessoria de imprensa, para a continuidade dessa sua exploração" (Sujeito J).

A vivência de sofrimento relativa à sociedade onde se escraviza envolve temas relacionados à formação escravocrata da sociedade brasileira e sua permanência na contemporaneidade sociocultural, além de temas econômicos que, na visão dos libertadores, favorecem a escravidão. Foi indicada por verbalizações como: "Se em determinado lugar se colocar uma placa: 'Aceitam-se trabalhadores escravos', vai ter gente que vai se inscrever. Que não está indo iludida, entendeu? Então, infelizmente, é uma realidade econômica muito grave" (Sujeito J).

Para você ter uma ideia, de cada 100 trabalhadores no meio rural, mais de 80 não têm sequer carteira de trabalho assinada. Quer dizer, isso demonstra que, no meio rural, há uma ausência da aplicação dos direitos trabalhistas. E é nesse caldo de cultura, nesses milhões de brasileiros, que você vai encontrar a superexploração, que é o trabalho escravo... A terra está em mãos de poucos, né? Você vai numa fazenda aí, no Mato Grosso, Tocantins, Pará, as fazendas são de trinta mil alqueires de terra. Isso é uma coisa fabulosa, né? Famílias que vão ser exploradas ali, estão sendo exploradas como escravos (Sujeito A).

Em relação à categoria-síntese vivência de sofrimento, a Tabela 2 aponta as categorias presentes em cada entrevista, com o total das verbalizações de cada uma.

A vivência de sofrimento relativa à sociedade onde se escraviza correspondeu a $36 \%$ dos conteúdos verbalizados, a relativa à pessoa escravizada ocupou $34 \%$, e a relativa à pessoa que escraviza correspondeu a $30 \%$ das verbalizações.

A categoria-síntese vivência de prazer foi organizada em categorias relacionadas (a) ao liberto, (b) ao libertador e (c) à sociedade em que se liberta.

A vivência de prazer relativa à pessoa liberta engloba temas em que o libertador expressou felicidade com a libertação da pessoa submetida ao 
trabalho escravo, ou atribuiu-lhe características humanas positivas. Foi indicada por verbalizações como: "Por isso que eu falo, ainda assim, eles são muito fortes. Depois que você for considerar, e ver a cara deles, até que eles são muito fortes" (Sujeito D); "São especializados em trabalhar a terra, historicamente, assim, só fizeram isso, seus ascendentes todos só fizeram isso, e não têm terra, né?" (Sujeito A); "Quase toda semana, todo mês, a gente recebe agradecimentos dos sindicatos, dos trabalhadores, com satisfação, por ter resolvido o problema" (Sujeito I).

A vivência de prazer relativa à pessoa que liberta engloba temas relacionados à percepção que o libertador tem do retorno positivo de seu trabalho, articulado em função de seus próprios recursos como profissional, e da visão positiva que desenvolve sobre si mesmo. Foi indicada por verbalizações como: "Eu assumo essa missão, sabe? Na minha vida, de buscar fazer com que a gente tenha um mundo melhor" (Sujeito J); "A gente se sente valorizada sim, por cada peça ... aquilo que eu te falei" (Sujeito H); "A gente se sente sim, reconhecido, e, para mim, graças a Deus, tem sido uma honra trabalhar aqui" (Sujeito B).

$A$ vivência de prazer relativa à sociedade onde se liberta envolve temas relacionados à transformação da realidade brasileira, com vistas a uma conscientização do povo e abertura de perspectivas que levem

Tabela 2 - Quadro-resumo das categorias por entrevista - vivência de sofrimento

\begin{tabular}{cccc}
\hline Entrevistas & $\begin{array}{c}\text { Pessoa } \\
\text { escravizada }\end{array}$ & $\begin{array}{c}\text { Pessoa que } \\
\text { escraviza }\end{array}$ & $\begin{array}{c}\text { Sociedade } \\
\text { que escraviza }\end{array}$ \\
\hline A & 2 & 0 & 3 \\
B & 23 & 51 & 41 \\
C & 17 & 6 & 3 \\
\hline D & 2 & 0 & 28 \\
\hline E & 57 & 52 & 75 \\
\hline F & 41 & 19 & 26 \\
\hline G & 7 & 0 & 6 \\
\hline H & 58 & 36 & 40 \\
\hline I & 12 & 21 & 5 \\
\hline J & 3 & 11 & 5 \\
\hline Total & $\mathbf{2 2 2}$ & $\mathbf{1 9 6}$ & $\mathbf{2 3 2}$ \\
\hline
\end{tabular}

Fonte: Dados da pesquisa. ao fim da escravidão. Foi indicada por verbalizações como: "O que tem destacado o Brasil, nesse processo, é que o Brasil é um dos únicos países que reconhece a escravidão no país. E tem tomado medidas governamentais para erradicação da escravidão" (Sujeito A); "O Brasil está avançando muito no combate ao trabalho escravo" (Sujeito G);

A gente percebeu, também, que depois da morte dos fiscais do trabalho em Unaí, eles deram muita visibilidade na mídia, muita. Então foi bom, porque a gente tem a nossa campanha. Foi bom entre aspas, né? Precisou morrer, para darem a visibilidade, para o governo dar mais atenção ao tema (Sujeito E).

A Tabela 3 aponta as categorias presentes em cada entrevista, com o total das verbalizações de cada uma.

A categoria de vivência de prazer relativa ao libertador ocupou 53\% dos conteúdos verbalizados, seguida de vivência de prazer relativa à sociedade que liberta (43\%), e vivência de prazer com relação à pessoa liberta (4\%).

Considerando-se todas as categorias-síntese, 51\% dos conteúdos expressos pelos libertadores se referiam à vivência de sofrimento, 34\% à organização do trabalho e $15 \%$ à vivência de prazer.

Tabela 3 - Quadro-resumo das categorias por entrevista - vivência de prazer

\begin{tabular}{cccc}
\hline Entrevistas & Liberto & Libertador & $\begin{array}{c}\text { Sociedade } \\
\text { que liberta }\end{array}$ \\
\hline A & 1 & 2 & 0 \\
B & 0 & 20 & 5 \\
C & 0 & 14 & 3 \\
\hline D & 0 & 5 & 17 \\
\hline E & 2 & 0 & 22 \\
\hline F & 2 & 9 & 8 \\
\hline G & 0 & 2 & 0 \\
\hline H & 2 & 22 & 2 \\
\hline I & 1 & 15 & 13 \\
\hline J & 0 & 15 & 14 \\
\hline Total & $\mathbf{8}$ & $\mathbf{1 0 4}$ & $\mathbf{8 4}$ \\
\hline
\end{tabular}

Fonte: Dados da pesquisa. 


\section{Discussão}

Os resultados evidenciam que a vivência de prazer está relacionada fundamentalmente com sentimentos de realização pessoal, de ter evidenciada sua capacidade de transformação das pessoas e do meio social. Considera-se que, sendo a organização do trabalho do libertador altamente dinâmica e voltada ao sucesso, esta se apresenta como um fator que favorece a vivência do prazer no trabalho.

0 predomínio de vivências de sofrimento é manifesto por sentimentos como a mágoa com relação à falta de condições de trabalho dos escravos, raiva e sensação de asco frente ao escravista e insatisfação com as condições sociais desfavoráveis ao trabalho livre.

Tomando-se isoladamente as vivências de prazer e de sofrimento, os resultados reforçam que, apesar de serem construtos inseparáveis (Morrone, 2001), a vivência de prazer do libertador e a de sofrimento se articulam de formas particulares.

O escravagista e o escravo são representados pelo libertador com imagens menos positivas do que aquelas com as quais ele se representa. Um dos fatores mais ressaltados pelos libertadores, no referente aos escravos, é a taxa de reincidência. Os libertadores demonstram insatisfação e ressentimento ao relatar que, mesmo após terem sido libertos, um número considerável de pessoas é novamente aliciado para o trabalho escravo ou se submete voluntariamente, seja por total incapacidade de encontrar trabalho, seja por "vergonha" de voltar à família depois de ter sido escravizado.

A Teoria de Avaliação Cognitiva (Deci, 1971), segundo a qual recompensas extrínsecas podem diminuir a motivação intrínseca, apresenta-se como um possível parâmetro teórico para compreender essa reincidência em torno de $20 \%$ em todo o Brasil, aumentando para $40 \%$ quando tomado apenas o estado do Pará (MTE, 2004).

Os conceitos de legitimação da desigualdade (Pratto et al., 2000), de construção do Eu em situações de conflito (Derlega, Kuang, Cukur \& Forsyth, 2002) e de sentimento de auxílio moral (Baron \& Miller, 2000) podem servir de parâmetros para entender como se desenvolvem as percepções dos libertadores no contexto da escravidão.

Conjugando-se essas abordagens, tem-se que: (a) a persistência na legitimação da desigualdade deve ser buscada em sociedades com forte hierarquia; (b) a identidade da pessoa persiste, mesmo que por vieses coletivistas, em situações críticas; (c) culturas coletivistas como a brasileira tendem a ver mais obrigações em ajudar do que as individualistas, apesar de que em países individualistas as pessoas tendem a confiar mais nas outras (Allik \& Realo, 2004).

Com base na proposta de Jovchelovitch (2000) de organizar graficamente redes de temas e explicações, a Figura 1 apresenta o campo representacional dos libertadores.

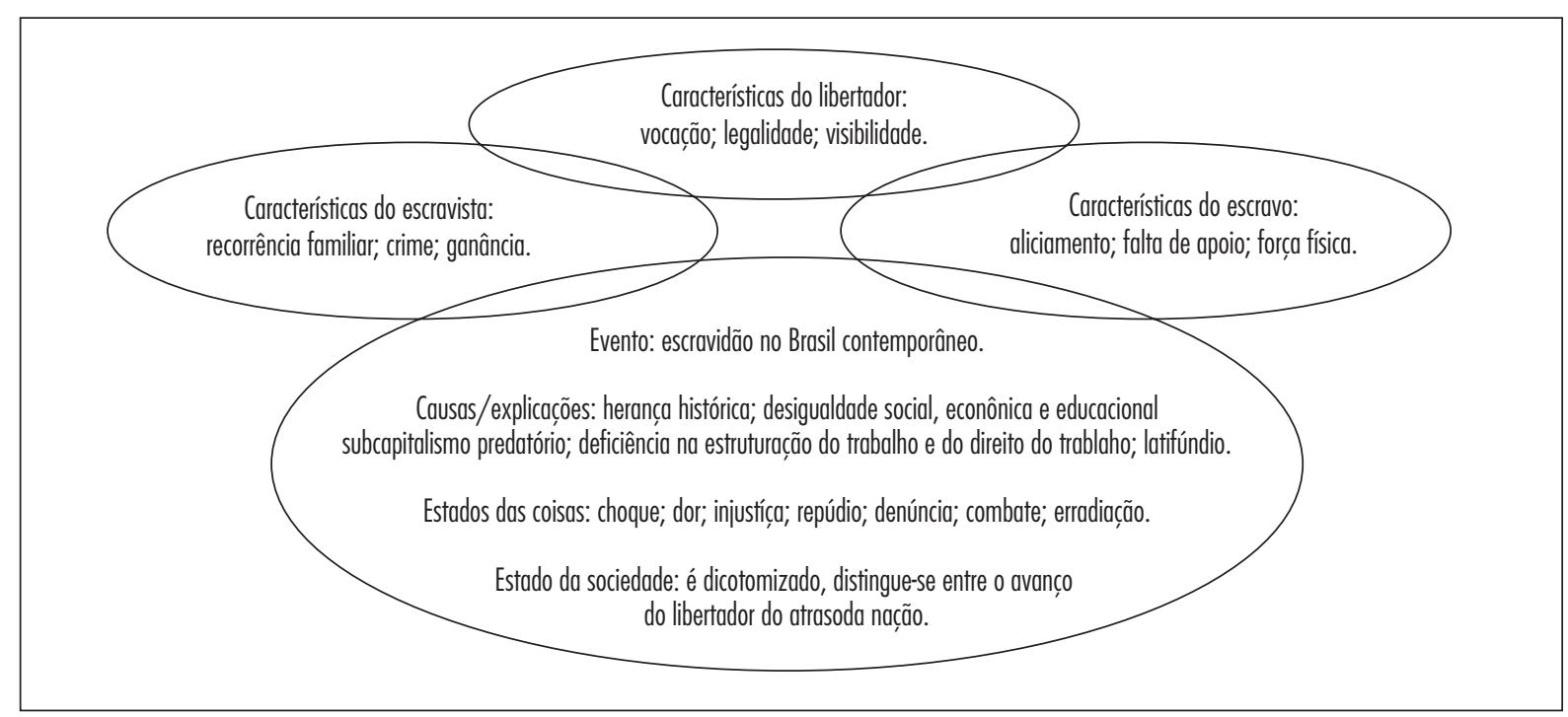

Figura 1 - Campo representacional dos libertadores Fonte: Dados da pesquisa. 
A percepção dos libertadores quanto às vivências de prazer e de sofrimento dos libertos influencia positivamente as suas próprias vivências. 0 valor atribuído à organização do trabalho dos libertadores é relacionado à eficácia do libertador na transformação das pessoas escravizadas em pessoas libertas, ou seja, na transformação do trabalho escravo em trabalho livre.

Quanto à organização do trabalho, a vivência de prazer é maior que a de sofrimento. A dinâmica do trabalho requer profundo envolvimento intelectual e controle emocional por parte dos responsáveis para a devida consecução das metas de libertação.

A vivência de sofrimento, mecanismo de alta mobilização subjetiva, é distribuída de forma semelhante entre as categorias, com maior acento para o sofrimento ante a percepção de uma sociedade onde se escraviza, não significativamente maior que o referente à pessoa escravizada e o escravista.

No que se refere ao processo de decadência e superação da escravidão moderna em prol do surgimento do capitalismo industrial, "as economias escravistas geralmente manifestam tendências irracionais que inibem o desenvolvimento econômico e põem em risco a estabilidade social" (Genovese, 1976, p. 21). Por outros termos, por mais tênue que seja o contato dos indivíduos com a escravidão, esta gera incerteza e, consequentemente, dissonância cognitiva e evitação da incerteza. Esse é um fator para a predominância das vivências de sofrimento entre os libertadores, reforçando a aversão à estrutura escravocrata.

Os libertadores, indivíduos com elevado grau de escolaridade e participantes do processo de globalização, sofrem demasiadamente com a dissonância cognitiva decorrente da interação com uma conjuntura social irracional.

A vivência de prazer dos libertadores está relacionada às estratégias de defesa dos indivíduos, como a autovalorização de seu trabalho como libertador, e à percepção de uma sociedade onde se liberta.

0 funcionamento psíquico dos libertadores não é livre de influências de prazer e/ou de sofrimento enquanto não há a percepção de que os mecanismos sociais de libertação funcionam, através da satisfação das necessidades e desejos dos escravos, o que só é percebido como real quando estes são libertos.

As vivências de prazer são significativas, e junto à percepção da organização do trabalho formam um equilíbrio entre o desgaste causado pelo trabalho e as expectativas positivas de transformação da realidade brasileira.

0 liberto tem um papel primordial não apenas na definição do cargo do libertador, mas também, e fortemente, na identidade profissional do libertador, e em como ele se percebe e percebe a sociedade brasileira.

0 libertador, ao libertar o outro, também é libertado, tanto pessoal quanto profissionalmente. A sociedade muda para quem liberta, porque possibilita a assunção de vivências de prazer, as quais são impossibilitadas enquanto o outro é escravizado. A perspectiva da libertação, com o sucesso no combate ao trabalho escravo, reforça o libertador, de modo que se justifica o seu empenho em libertar, apesar de altamente sofrido.

Pode-se também fazer uma leitura desses resultados a partir do referencial da "ideologia", definida por Guareschi (2002, p. 97) como um aspecto da vida social caracterizado pelas maneiras como o sentido das concepções serve para estabelecer e sustentar relações de dominação, entendida como a relação que se dá pela expropriação do outro, privando-o injustamente de determinados benefícios.

Considerando-se a Psicodinâmica do Trabalho como olhar "singular para o sofrimento que antecede a formação de sintomas" (Karam, 2010, p. 57), conclui-se que o trabalho de libertar, apesar da ampla diversidade ocupacional dos libertadores contemporâneos (governo, organizações não governamentais e organismos internacionais), tem um fator ativo na desestruturação de relações de dominação. Além disso, esse potencial de apoderamento do outro, como relação intersubjetiva, traz poder ao libertador nessa relação.

\section{Considerações finais}

Na percepção dos libertadores, os escravistas não definem como explorador o regime de trabalho a que submetem seus empregados. Caracterizamno como justo. Suas alegações remetem a duas ideias: (1) a de incapacidade dos oprimidos, manifesta como a impossibilidade de encontrarem outro trabalho que não aquele; e (2) a de incapacidade do Estado brasileiro de disponibilizar trabalho digno para tais pessoas. 
O libertador expõe, por meio da fala, a imagem/ representação social que tem do escravista, visto como pessoa que percebe a ineficácia do Estado, e aproveitando-se conscientemente dessa lacuna, encontra espaços para explorar os "incapazes".

De acordo com estudos de justiça nas organizações (Paz, 1999), considera-se que a preocupação das pessoas em serem recompensadas de acordo com o aumento de sua produtividade é ambiente que propicia o surgimento de conflitos. A fim de apaziguá-los, é necessário um conjunto de normas que assegurem a distribuição, considerada correta, dos benefícios. Essa distribuição não ocorre no contexto do trabalho escravo, o que acentua a visão negativa que se tem dos escravistas, como mais do que maus empregadores, também como pessoas más.

0 fenômeno denominado "zona muda" (Abric, 2003) abre perspectivas que auxiliariam a compreender melhor as representações sociais dos opressores, porventura fosse possível entrevistá-los. 0 temor de "dar uma má imagem de si mesmos" leva algumas pessoas a não se pronunciarem diretamente acerca de suas reais volições e pensamentos, quando relacionados a certos objetos e contextos contranormativos.

Na representação construída pelo libertador sobre o escravista, fica sugerida essa zona muda, referente à justificação do trabalho escravo por parte do opressor. Essa é uma hipótese que poderia ser testada a partir de investigação das representações sociais dos escravocratas contemporâneos.

\section{Referências}

Abric, J.-C. (2003). La recherche du noyau central et de la zone muette des représentations sociales. In J.-C., Abric (Org.). Méthodes d'étude des représentations sociales. (pp. 13-35). France: Éditions érès.

Agrolink. (2011). Cotações de commodities agrícolas. Recuperado em 24 abr. 2011, de http://www.agrolink.com.br/cotacoes/pg_media30.asp.

Allik, J., \& Realo, A. (2004). Individualism-collectivism and social capital. Journal of Cross-Cultural Psychology, 35(1), 29-49. doi:10.1177/0022022103260381.

Allport, G. (1954). The nature of prejudice. Reading, MA: Addison-Wesley. PMid:13204492.
Alves, L. M. A. (2004). Sonhar e fazer: experiências de mulheres e de homens em movimentos sociais, na luta por moradia em Rondonópolis - MT (1974-1989). Tese de Doutorado, Departamento de História, Instituto de Ciências Humanas da Universidade de Brasília, Brasília.

Bardin, L. (1995). Análise de conteúdo. Lisboa: Edições 70.

Baron, J., \& Miller, J. G. (2000). Limiting the scope of moral obligations to help: A cross-cultural investigation. Journal of Cross-Cultural Psychology, 31(6), 703-725. doi:10.1177/0022022100031006003.

Comissão Pastoral da Terra (2003). Primeira denúncia de trabalho escravo no Brasil. Goiânia: Ed. do Autor.

Conrad, R. (1975). Os últimos anos da escravidão no Brasil. Rio de Janeiro: Civilização Brasileira.

Davis, D. B. (2001). O problema da escravidão na cultura ocidental. Rio de Janeiro: Civilização Brasileira.

Deci, E. L. (1971). Effects of externally mediated rewards on intrinsic motivation. Journal of management, 12(2), 203-222.

Derlega, V. J., Kuang. J. C. Y., Cukur, C. S., \& Forsyth, D. R. (2002). Interdependent construal of self and the endorsement of conflict resolution strategies in interpersonal, intergroup, and international disputes. Journal of Cross-Cultural Psychology, 33(6), 610-625. doi10.1177/0022022102238272.

Dupas, G. (1998). A questão do emprego e da exclusão social na lógica da economia global. In P. S. Pinheiro \& S. P. Guimarães (Org.). Direitos humanos no século XXI. (pp. 107-132). Rio de Janeiro: Instituto de Pesquisa de Relações Internacionais.

Fernandes, F. (1979). Anotações sobre o capitalismo agrário e a mudança social no Brasil. In T. Szmrecsányi \& O. Queda (Org.). Vida rural e mudança social. (pp. 105-120). São Paulo: Companhia Editora Nacional.

Fiabani, A. (2005). Mato, palhoça e pilão: O quilombo, da escravidão às comunidades remanescentes (15322004). São Paulo: Expressão Popular.

Figueira, R. R. (2001). Emigração no Piauí: O aliciamento para a escravidão. Brasília: Rede Social de Justiça e Direitos Humanos. PMCid:1850299.

Figueira, R. R. (2004). Pisando fora da própria sombra: $A$ escravidão por dívida no Brasil contemporâneo. Rio de Janeiro: Civilização Brasileira. 
Genovese, E. (1976). A economia política da escravidão. Rio de Janeiro: Pallas.

Girardi, G. (1996). Os excluídos construirão a nova história? O movimento indígena, negro e popular. São Paulo: Ática. PMCid:2398479.

Guareschi, P. (2002). Ideologia. In M. G. C. Jacques, M. N. Strey, M. G. Bernardes, P. A. Guareschi, S. A. Carlos \& T. M. G. Fonseca (Org.). Psicologia social contemporânea. (pp. 89-103). Petrópolis: Vozes.

James, C. L. R. (2000). Os jacobinos negros: Toussaint L'Ouverture e a revolução de São Domingos. São Paulo: Boitempo Editorial.

Jones, J. (1997). Prejudice and racism. New York: McGraw-Hill.

Jovchelovitch, S. (2000). Representações sociais e esfera pública. Petrópolis: Vozes.

Karam, H. (2010). Desafio para a psicodinâmica do trabalho no Brasil: Um ponto de vista. In A. M. Mendes, A. R. C. Merlo, C. F. Morrone \& E. P. Facas (Org.). Psicodinâmica e clínica do trabalho: Temas, interfaces e casos brasileiros. (pp. 53-60). Curitiba: Juruá

Meltzer, M. (2003). História ilustrada da escravidão. Rio de Janeiro: Ediouro.

Mendes, A. M., \& Morrone, C. F. (2002). Vivências de prazer-sofrimento e saúde psíquica no trabalho: Trajetória conceitual e empírica. In A. M. Mendes, L. 0. Borges \& M. C. Ferreira (Org.). Trabalho em transição, saúde em risco. (pp. 25-42). Brasília: Editora Universidade de Brasília. PMid:11788927.

Mendes, A. M., \& Morrone, C. (2010). Trajetória teórica e pesquisas brasileiras sobre prazer e sofrimento no trabalho. In A. M. Mendes, A. R. C. Merlo, C. F. Morrone \& E. P. Facas (Org.). Psicodinâmica e clínica do trabaIho: Temas, interfaces e casos brasileiros. (pp. 29-52). Curitiba: Juruá.

Ministério do Trabalho e Emprego, [MTE], (2004). Fiscalização do trabalho escravo em fazendas. Brasília: Ed. do Autor.

Ministério do Trabalho e Emprego, [MTE], (2011). Quadro geral das operações de fiscalização para erradicação do trabalho escravo - SITE/SRTE - 1995 a 2010. Brasília: Ed. do Autor. Recuperado em 24 abr. 2011, de http://portal.mte.gov.br/data/files/FF8080812B 2F46A8012B2FB55D635C4D/99F4876Ed01.pdf
Mir, L. (2004). Guerra civil: Estado e trauma. São Paulo: Geração Editorial.

Morrone, C. F. (2001). 'Só para não ficar desempregado' - Ressignificando o sofrimento psíquico no trabalho: Estudo com trabalhadores em atividades informais. Dissertação de Mestrado, Instituto de Psicologia da Universidade de Brasília, Brasília.

Moscovici, S. (1981). Psicologia de las minorias activas. Madrid: Ediciones Morata.

Moura, C. (1959). Rebeliões da senzala: Quilombos, insurreições, guerrilhas. São Paulo: Zumbi.

Oliveira, F., \& Werba, G. (2002). Representações sociais. In M. G. C. Jacques, M. N. Strey, N. M. G. Bernades, P. A. Guareschi, S. A. Carlos \& T. M. G. Fonseca. (Org.). Psicologia social contemporânea. (pp. 104-117). Petrópolis: Vozes.

Paiva, L. (2003). Brasil intensifica combate ao tráfico de seres humanos. Brasília: Secretaria Nacional de Justiça.

Paz, M. G. T. (1999). Justiça no trabalho e poder organizacional. In M. G. T. Paz \& A. Tamayo (Org.). Escola, saúde e trabalho: Estudos psicológicos. (pp. 271-294). Brasília: Ed. UnB.

Pereira, J. (2003). Vivências de prazer e sofrimento na atividade gerencial em empresa estratégica: $\mathrm{O} \mathrm{im}$ pacto dos valores organizacionais. Dissertação de Mestrado, Instituto de Psicologia da Universidade de Brasília, Brasília.

Pratto, F., Liu, J. H., Levin, S., Sidanius, J., Shih, M., Bachrach, H., et al. (2000). Social dominance orientation and the legitimization of inequality across cultures. Journal of Cross-Cultural Psychology, 31(3), 369-409. doi:10.11 77/0022022100031003005.

Procuradoria Federal dos Direitos do Cidadão, [PFDC], (2003). Planilha PFDC - fazendas fiscalizadas. Brasília: Autor.

Schiochet, V. (1999). O social pensado politicamente. A noção de sociedade civil e sua condição de inteligibilidade. Tese de Doutorado, Departamento de Sociologia, Instituto de Ciências Sociais da Universidade de Brasília, Brasília.

Sorj, B., Pompermayer, M. J., \& Coradini, O. L. (1982). Camponeses e agroindústria: Transformação social e representação política na avicultura brasileira. Rio de Janeiro: Ed. Jorge Zahar. 
Véras, M. (2002). Exclusão social - Um problema brasileiro de 500 anos (notas preliminares). In B. Sawaia (Org.). As artimanhas da exclusão. (pp. 27-50). Petrópolis, RJ: Vozes.
Vidor, G. (2005, 17 jan.). Soja no azul. Jornal O Globo, p. 16. (Seção de Economia). 